\title{
EDITORIAL
}

\section{Maternal and Newborn Mortality- Still the Greatest Disparity between Low-Income and High-Income Countries}

\section{Abraham Haileamlak, MD, Professor of Pediatrics and Child Health}

Maternal and newborn mortality remains a major challenge to health systems of low-income countries. Of all health indicators, maternal and newborn mortalities show the greatest disparity between low-income and high-income countries (1). The main reason for this is women in lowincome countries are in a lifetime risk of dying from a pregnancy and delivery-related complications. This is true because of poor health service coverage where high risk mothers do not have access to institutional delivery; even if they have access quality of care is poor. Of over 200 million women conceiving each year, about a seventh of them are likely to develop complications where these complications are fatal to a significant number of them. In line with this, millions of newborns either die, or survive with disabilities (2).

More than $99 \%$ of these maternal and newborn demises occur in low-income countries (1). Before and in the early twentieth century, maternal and newborn mortality in the current high-income countries were similar to the one in low-income countries today (3), since their health system was like that of the current low-income countries. Since the mid and late twentieth century, economically developed countries invested a lot in improving health care in general but for mothers and newborns in particular. As a result, they almost eliminated maternal and newborn deaths due to pregnancy and delivery related complications.

It is an established fact that pregnancy and delivery-related complications and their consequences can only be prevented by skilled care during pregnancy, delivery and afterwards $(4,5)$. This should be complemented with the availability of essential drugs, supplies, equipment and referral systems. In addition, creating a community that owns its health is imperative. However, in large parts of the world, skilled antenatal, natal and postnatal care is not possible for many of others. The absence of such a coordinated effort leads mothers and newborns loss of their lives. Therefore, the low-income countries should not reinvent the wheel; they have to learn from the others' history of fasten the investment to improve the health system.

The current issue of the journal, the fourth regular issue for the year 2018, contains an editorial, fourteen original articles, a review and a case report focusing on various topics. Three of the original articles, in one way or another, deal with maternal and newborn health.

I invite readers to read through these articles and appreciate or utilize the contents. I also encourage readers to forward comments and suggestions to the editor or the corresponding authors.

\section{REFERENCES}

1. WHO, UNFPA, UNICEF, World Bank (2012) Trends in Maternal mortality from 1990 to 2010. Geneva, Switzerland.

2. World Health Organization. Research on Reproductive Health at WHO: Biennial Report 2000-2001. Geneva: WHO, 2002

3. LoudonI. Maternal mortality in the past and its relevance to the developing world today. Am J ClinNutr, 2000; 72: 241S-246S

4. WHO. Making pregnancy safer: the critical role of the skilled attendant. Jt Statement WHO ICM FIGO Geneva. 2004;

5. WHO. MDG 5: improve maternal health. In: WHO [Internet]. 2013 (Accessed on June 2018).

Available: http://www.who.int/topics/millenn ium development goals/maternal health/en/ 